\title{
IMPLEMENTASI METODE K-NEAREST NEIGHBOR (KNN) UNTUK SELEKSI CALON KARYAWAN BARU (Studi Kasus : BFI Finance Surabaya)
}

\author{
Adhitya Rahmat D.N, Karina Auliasari, Yosep Agus Pranoto \\ Program Studi Teknik Informatika S1, Fakultas Teknologi Industri \\ Institut Teknologi Nasional Malang, Jalan Raya Karanglo km 2 Malang, Indonesia \\ adhityardnugraha67@gmail.com
}

\begin{abstract}
ABSTRAK
Proses seleksi merupakan salah satu cara penting yang digunakan untuk memilih yang terbaik. Proses seleksi yang dilakukan BFI Finance Surabaya meliputi beberapa proses, proses tersebut antara lain seleksi CV, tes psikologi, interview, offering letter, cek kesehatan, dan terakhir tanda tangan kontrak. Masalah yang timbul dari proses seleksi ini seperti berkas yang masuk banyak, terdapat kemiripan penilaian calon karyawan, tidak memenuhi panggilan interview, tidak mengerjakan tes psikologi, sudah diterima tempat lain dan bad altitude. Akibat dari permasalahan tersebut adalah proses seleksi yang dilakukan perusahaan dirasa memakan waktu yang lama dan kurang efektif, sehingga menjadi masalah dalam rekrutmen karyawan.

Permasalahan tersebut menjadi latar belakang dilakukannya pengembangan dan pembuatan program seleksi calon karyawan berbasis web yang memudahkan dalam klasifikasi data karyawan baru yang termasuk dalam kategori lolos atau tidak lolos. Dengan menggunakan sistem ini diharapkan dapat membantu pihak HRD dalam mengolah data karyawan dengan tepat dan akurat.

Berdasarkan hasil pengujian sistem yang telah dilakukan, perhitungan manual yang dilakukan menggunakan Microsoft Excel dengan perhitungan yang dilakukan oleh sistem menghasilkan persentase 100\%. Dan hasil perhitungan algoritma K- Nearest Neighbor dengan nilai parameter K = 7 menggunakan metode Euclidean Distance didapat nilai akurasi sebesar $91 \%$, nilai presisi sebesar $87 \%$, dan nilai recall sebesar $100 \%$.
\end{abstract}

Kata kunci : KNN, K-Nearest Neighbor, Seleksi, Karyawan Baru, Euclidean Distance, Klasifikasi

\section{PENDAHULUAN}

Karyawan merupakan komponen penting yang dimiliki oleh sebuah perusahaan. Untuk menentukan karyawan tentunya pihak perusahaan akan menyeleksi calon karyawan dengan akurat agar karyawan yang diterima sesuai dengan apa yang dibutuhkan oleh perusahaan. Perusahaan biasanya akan memberikan syarat - syarat apa saja yang dibutuhkan untuk calon karyawan. Proses seleksi yang dilakukan BFI Finance Surabaya meliputi beberapa proses, proses tersebut antara lain seleksi $\mathrm{CV}$, tes psikologi, interview, offering letter, cek kesehatan, dan terakhir tanda tangan kontrak.

Dalam menyeleksi berkas - berkas lowongan, pihak HRD akan melihat satu persatu berkas tersebut, kemudian akan menilai berkas pelamar mana yang layak masuk dalam kategori perusahaan. Masalah yang timbul dari proses seleksi ini seperti berkas yang masuk banyak, kemudian apabila pelamar lolos tahap seleksi CV, pihak HRD bingung apabila terdapat kemiripan penilaian calon karyawan, tidak memenuhi panggilan interview, tidak mengerjakan tes psikologi, sudah diterima tempat lain dan bad altitude. Akibat dari permasalahan tersebut adalah proses seleksi yang dilakukan perusahaan dirasa memakan waktu yang lama dan kurang efektif, sehingga menjadi masalah dalam rekrutmen karyawan.

Permasalahan tersebut menjadi latar belakang dilakukannya pengembangan dan pembuatan program seleksi calon karyawan berbasis web yang memudahkan dalam klasifikasi data karyawan baru yang termasuk dalam kategori lolos atau tidak lolos. Dengan menggunakan sistem ini diharapkan dapat membantu pihak HRD dalam mengolah data karyawan dengan tepat dan akurat.

Pada Data Mining banyak jenis algoritma yang dapat dilakukan untuk mengolah data - data, salah satunya berdasarkan tugas yang dilakukan yaitu klasifikasi. Algoritma yang termasuk dalam klasifikasi antara lain pohon keputusan C4.5, Naïve Bayes, Neural Network, Logistic Regreesion dan KNN. K-Nearest Neighbor (KNN) merupakan metode yang termasuk kelompok dalam pengklasifikasian data yang sederhana dan mudah untuk pengimplementasian, efektif pada data yang lebih besar, dan dapat mengklasifikasikan data dengan tepat. Maka dari itu metode KNN sesuai dengan data yang digunakan dalam penelitian ini.

Berdasarkan permasalahan yang dikemukakan di atas, maka penelitian ini bertujuan untuk merancang dan mengimplementasikan sistem pendukung keputusan untuk menyeleksi karyawan baru pada BFI Finance Surabaya. Kemudian dalam penelitian ini diterapkan metode $\mathrm{K}$ - Nearest Neighbor untuk menyeleksi karyawan baru pada BFI Finance Surabaya sehingga memudahkan pihak manajemen untuk melakukan klasifikasi karyawan baru lolos atau tidak lolos. 


\section{TINJAUAN PUSTAKA}

\subsection{Penelitian Terdahulu}

Berdasarkan penelitian yang dilakukan Wayan dan kawan - kawan pada tahun 2019, yang berjudul "Implementasi K-Nearest Neighbor pada penentuan keluarga miskin bagi dinas sosial kabupaten Tabanan", tingginya angka kemiskinan di Kabupaten Tabanan yang mencapai 5\% membuat Dinas terkait untuk mengatasinya, namun program pengentasan kemiskinan yang sudah dilakukan masih belum optimal karena data yang digunakan sebagai acuan tidak akurat. Untuk mengatasinya dibuatlah sistem yang dapat menentukan keluarga miskin dengan benar. Hasil pengujian dari 12 data diidentifikasi dan diklasifikasi oleh sistem dengan 2 perbedaan klasifikasi jika dibandingkan dengan proses manual, akurasi data yang dihasilkan sebesar 83,33\%[1].

Selanjutnya di tahun 2019, Raihan dan Adityo melakukan sebuah penelitian menerapkan metode KNearest Neighbor untuk mengklasifikasikan kinerja satpam berbasis web. Penelitian ini dilakukan untuk menunjang kinerja satpam agar tetap semangat dalam menjaga keamanan di suatu instansi atau tempat. Langkah - langkah yang dilakukan Raihan dan Adityo dalam membuat program ini antara lain mengumpulkan data setelah itu membuat desain dan membuat program kemudian melakukan uji coba menggunakan metode Black Box Testing. Hasil perhitungan menghasilkan nilai kebenaran sebesar 66,67\% dengan menggunakan 6 data uji dan 130 data latih[2].

Sebelumnya pada tahun 2017 Nihru dan kawan - kawan membuat program menggunakan perpaduan metode K - Nearest Neighbor dan Weighted Product untuk penerimaan calon guru dan karyawan tata usaha baru. Pengumpulan data menggunakan cara manual lah yang menjadi acuan untuk membuat program ini. Metode KNN digunakan untuk menentukan jarak dengan klasifikasi kriteria baik, sedang dan buruk. Kemudian hasil perhitungan diinputkan ke dalam proses Weighted Product untuk melakukan perangkingan yang masuk dalam penilaian pegawai terbaik. Hasil pengujian dengan membandingkan hasil seleksi calon pegawai dengan sistem pengujian precission dan recall diperoleh nilai akurasi $94 \%$ precission $100 \%$ dan recall $80 \%$ [3].

Beberapa pengujian pada penelitian metode KNearest Neighbour menggunakan beberapa teknik pengujian mulai dari membandingkan dengan perhitungan manual, black box testing hingga pengujian menggunakan parameter precission dan recall, sebetulnya ada teknik yang lain yang bias digunakan dalam menguji nilai akurasi metode menggunakan nilai MASE (mean absolute square error) seperti pada penelitian Karina dan Mariza untuk penentuan konsumen yang berpotensi yang dilakukan pada tahun 2019[4].

Pada tahun 2016 wardani dan kawan - kawan, membuat aplikasi yang berjudul "Aplikasi Klasifikasi Jenis Tumbuhan Mangrove Berdasarkan Karakteristik
Morfologi Menggunakan Metode K-Nearest Neighbor (KNN) Berbasis Web" dalam kasus diatas permasalahan yang muncul ialah banyaknya jenis tanaman mangrove yang berada di Indonesia, di Indonesia tercatat setidaknya terdapat 202 jenis tumbuhan mangrove, meliputi 89 jenis pohon, 5 jenis palma, 19 jenis pemanjat, 44 jenis herba tanah, 44 jenis epifit dan 1 jenis paku. Dari 202 jenis tersebut, 43 jenis (diantaranya 33 jenis pohon dan beberapa jenis perdu) ditemukan sebagai mangrove sejati (true mangrove), sementara jenis lain ditemukan disekitar mangrove dan dikenal sebagai jenis mangrove ikutan (asociate). Metode yang digunakan dalam penelitian ini pertama yaitu, studi literature kemudian melakukan pengumpulan data, selanjutnya data yang telah didapat dianalisis, selanjutnya melakukan perancangan untuk diimplementasikan pada sistem, dan terakhir adalah pengujian terhadap sistem. Hasil dari penelitian ini adalah berdasarkan pengujian yang dilakukan, keberhasilan yang didapatkan yaitu sebesar $77,77 \%$ [5].

\subsection{Dasar Teori}

\subsubsection{K-Nearest Neighbor (KNN)}

Algoritma K-Nearest Neighbor (KNN) adalah sebuah metode untuk melakukan klasifikasi terhadap objek berdasarkan data pembelajaran yang jaraknya paling dekat dengan objek tersebut. Teknik ini sangat sederhana dan mudah diimplementasikan. Mirip dengan teknik clustering, yaitu mengelompokkan suatu data baru berdasarkan jarak data baru itu ke beberapa data/tetangga terdekat[6].

Proses metode KNN dilakukan dengan mencari kelompok $\mathrm{k}$ objek dalam data training yang paling dekat dengan objek pada data baru atau data testing. Berikut langkah - langkah metode $\mathrm{K}$ - Nearest Neighbor :

1. Menentukan parameter $\mathrm{k}$ (jumlah tetangga paling dekat)

2. Menghitung jarak antara data yang akan dievaluasi dengan semua pelatihan

3. Mengurutkan jarak yang terbentuk

4. Menentukan jarak terdekat sampai urutan k

5. Memasangkan kelas yang bersesuaian

6. Mencari jumlah kelas dari tetangga yang terdekat dan menetapkan kelas tersebut sebagai kelas data yang akan dievaluasi

Untuk mencari jarak antara dua titik yaitu titik pada data training dan titik pada data testing, maka digunakan rumus Euclidean Distance dengan persamaan 2.1, sebagai berikut:

Persamaan 2.1 merupakan rumus untuk menghitung jarak pada metode K-Nearest Neighbor $(K N N)$ dengan Euclidien Distance :

$$
\begin{aligned}
& d(P, Q)=\sqrt{\sum_{i=1}^{n}\left(P_{i}-Q_{i}\right)^{2}} \\
& \text { Dimana } \\
& d(P, Q) \quad \text { :jarak euclidien }
\end{aligned}
$$




$\begin{array}{ll}\mathrm{n} & \text { :jumlah data training } \\ \mathrm{P} & \text { :inputan data ke }-1 \text { dari data } \\ \text { training } & \text { :inputan data ke }-1 \text { dari data testing } \\ \mathrm{Q} & \end{array}$

\subsubsection{Klasifikasi}

Klasifikasi merupakan proses penemuan model (fungsi) yang menggambarkan dan membedakan kelas data atau konsep yang bertujuan agar bisa digunakan untuk memprediksi kelas dari objek yang label kelasnya tidak diketahui.

Klasifikasi data terdiri dari 2 langkah proses. Pertama adalah learning (fase training), dimana algoritma klasifikasi dibuat untuk menganalisa data training lalu direpresentasikan dalam bentuk rule klasifikasi. Proses kedua adalah klasifikasi, dimana data tes digunakan untuk memperkirakan akurasi dari rule klasifikasi.

\section{METODE PENELITIAN}

\subsection{Blok Diagram Sistem}

Berikut ini adalah tampilan diagram blok sistem yang akan dibangun pada sistem seleksi calon karyawan baru dengan menggunakan metode $\mathrm{K}$ Nearest Neighbor

Alur dari diagram blok sistem ini pertama adalah admin harus login terlebih dahulu, setelah melakukan login admin dapat mengontrol data karyawan lama, pada tahap ini admin dapat mengupload, menambah mengedit dan menghapus data - data karyawan lama. Data karyawan lama ini digunakan untuk data latih pada perhitungan KNN. Setelah tahap control data karyawan lama, masuk ke tahap klasifikasi data, pada tahap ini data diolah menggunakan metode K- Nearest Neighbor. Tahap ini mencari klasifikasi terhadap calon karyawan apakah termasuk lolos atau tidak lolos. Setelah proses perhitungan, selanjutnya sistem akan menampilkan hasil klasifikasi calon karyawan baru.

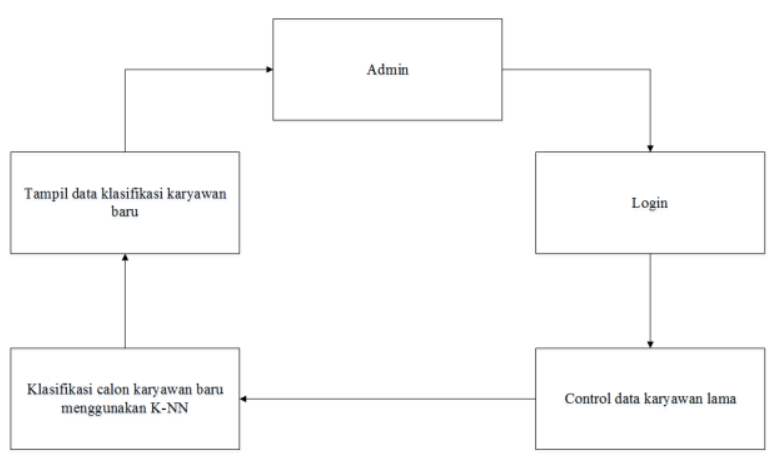

Gambar 1 Blok diagram sistem

\subsection{Flowchart K - Nearest Neighbor}

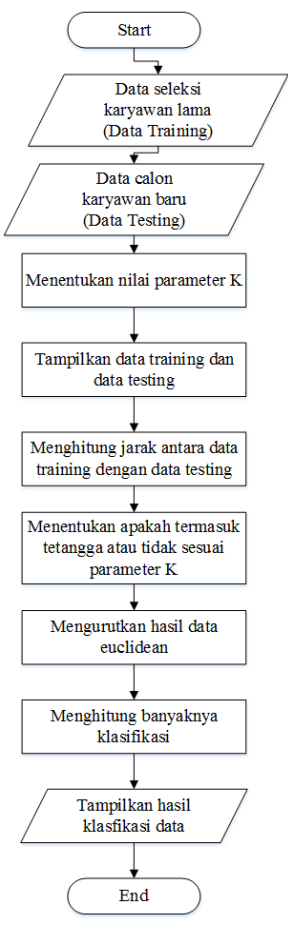

Gambar 2 Flowchart K - Nearest Neighbor

Pada gambar 2 adalah flowchart metode $K-$ Nearest Neighbor yang dimulai dari inputan data karyawan lama, kemudian menginput data calon karyawan. Setelah itu dilakukan proses perhitungan. Menentukan nilai parameter K. menampilkan data training dan data testing. Menghitung jarak antara data training dengan data testing. Menentukan apakah termasuk tetangga atau tidak sesuai parameter $\mathrm{K}$. Mengurutkan hasil data Euclidean. Kemudian akan keluar hasil dari seleksi calon karyawan baru.

\section{HASIL DAN PEMBAHASAN}

4.1 Tampilan Menu Data Karyawan Lama (Admin)

Di bawah ini merupakan tampilan menu data karyawan lama pada halaman admin, menu ini sekaligus menjadi menu utama pada halaman admin. Pada header terdapat logo dan beberapa pilihan menu, seperti data karyawan lama, data karyawan baru, hasil klasifikasi dan logout.

Terdapat tabel yang berisi data - data karyawan lama, kemudian terdapat 4 tombol, dua diantaranya terdapat diatas tabel, tombol ini digunakan untuk upload dan tambah data. Kemudian dua lainnya terdapat di tabel, tombol - tombol ini digunakan untuk proses update dan hapus data. 


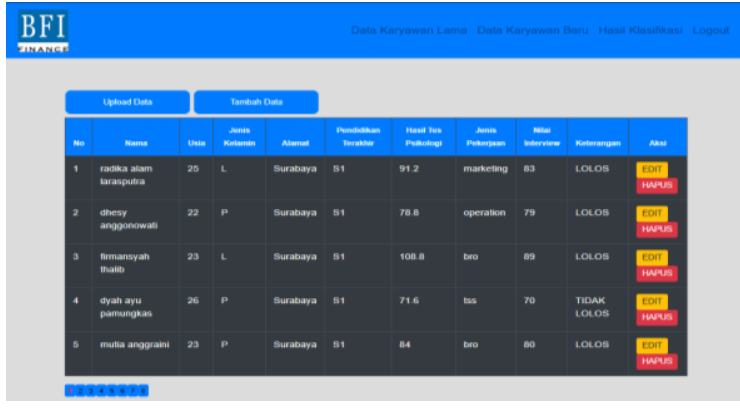

Gambar 3 Tampilan Menu Data Karyawan Lama (Admin)

\subsection{Tampilan Menu Data Karyawan Lama (Manager)}

Berikut tampilan halaman data karyawan lama pada halaman manager. Pada halaman ini hanya menampilkan data - data karyawan lama saja.

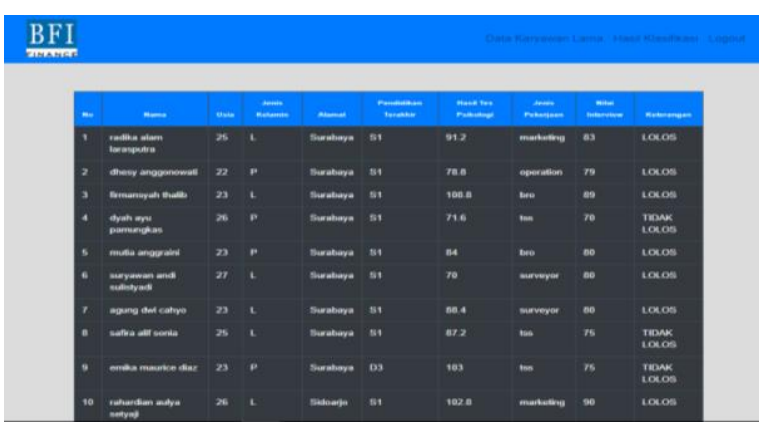

Gambar 4 Tampilan Menu Data Karyawan Lama (Manager)

\subsection{Tampilan Menu Data Karyawan Baru}

Sebelum melakukan proses klasifikasi, terlebih dahulu memasukkan data - data calon karyawan baru. Pada halaman inilah proses memasukkan data tersebut, pada halaman ini terdapat 7 text box. Text box pertama untuk memasukkan nilai parameter $\mathrm{K}$, kemudian id pelamar, nama, usia, alamat, hasil tespsikologi, dan hasil interview. Kemudian terdapat 3 combobox, masing - masing untuk jenis kelamin, pendidikan terakhir, dan jenis pekerjaan. Dan terdapat 1 tombol untuk melakukan proses perhitungan.

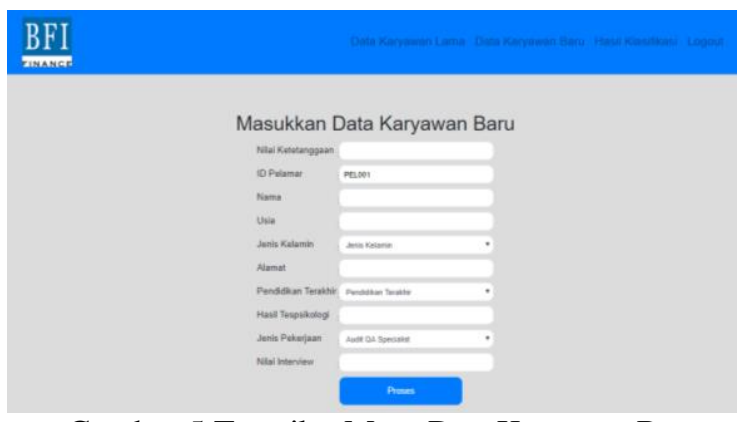

Gambar 5 Tampilan Menu Data Karyawan Baru

\subsection{Tampilan Hasil Klasifikasi (Admin)}

Pada halaman hasil klasifikasi ini menampilkan hasil proses perhitungan metode $K$ - Nearest Neighbor. Terdapat tabel yang berisi data - data calon karyawan baru beserta hasil klasifikasi. Kemudian terdapat tombol untuk menghapus data data tersebut.

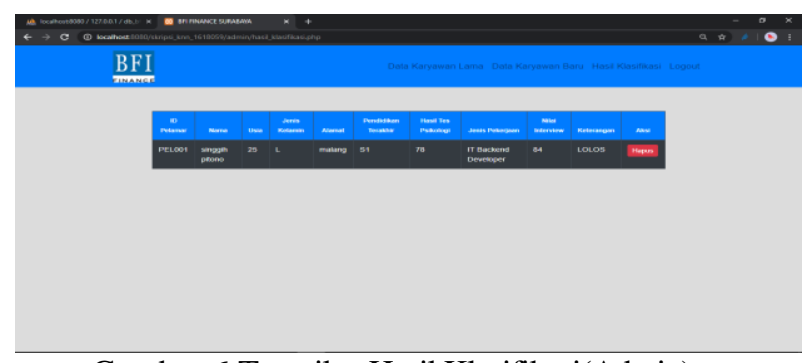

Gambar 6 Tampilan Hasil Klasifikasi(Admin)

\subsection{Tampilan Hasil Klasifikasi (Manager)}

Sama dengan halaman hasil klasifikasi pada halaman admin, yang membedakan ialah halaman ini hanya menampilkan hasil klasifikasi saja tanpa bisa melakukan proses apapun.

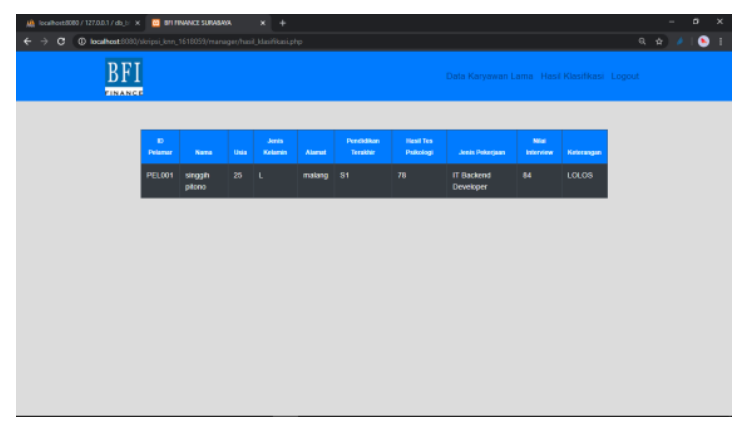

Gambar 7 Tampilan Hasil Klasifikasi(Manager)

\subsection{Tampilan Proses Perhitungan}

Halaman perhitungan merupakan halaman dimana admin menginputkan nilai kriteria (data calon karyawan baru).

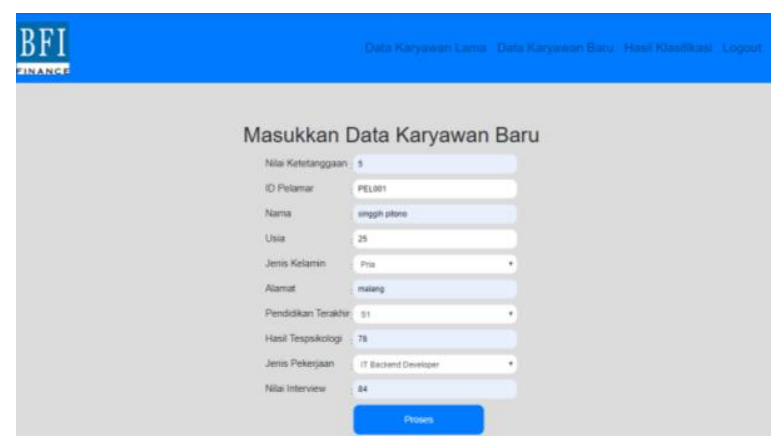

Gambar 8 Tampilan proses perhitungan 


\subsection{Tampilan Proses Klasifikasi}

Di bawah ini merupakan tampilan hasil klasifikasi dari perhitungan yang dilakukan oleh sistem.

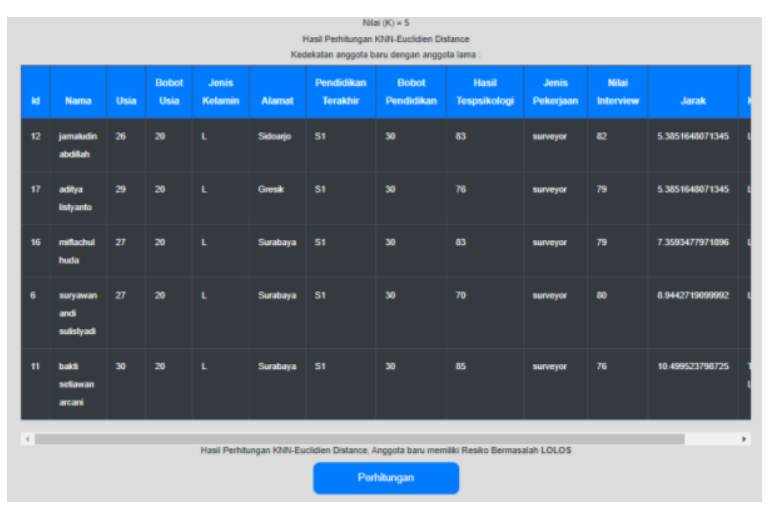

Gambar 9 Tampilan hasil proses klasifikasi

\subsection{Tampilan Hasil Perhitungan}

Berikut adalah tampilan hasil perhitungan dari sistem, pada hasil perhitungan ini data hasil perhitungan diurutkan berdasarkan jarak yang terkecil ke terbesar.

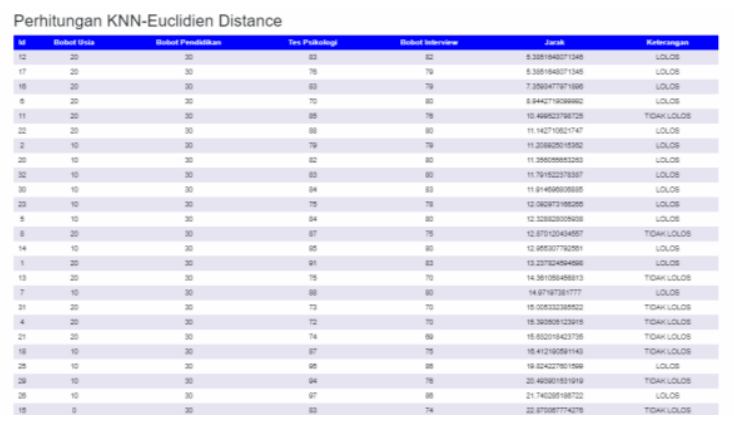

Gambar 10 Tampilan hasil perhitungan

\subsection{Hasil Pengujian Algoritma}

Pada pengujian algoritma ini menggunakan Confusion Matrix, Confusion Matrix adalah suatu metode yang dapat digunakan untuk mengukur kinerja suatu metode klasifikasi.

Dari jumlah data total sebanyak 65 data, didapat data lolos yang terdeteksi benar sebanyak 40, data lolos yang diklasifikasi tidak lolos sebanyak 0 , data tidak lolos yang diklasifikasi lolos sebanyak 6, dan data tidak lolos yang terdeteksi benar sebanyak 19 . Penjelasan Confusion Matrix dapat disajikan pada Tabel 1.

Tabel 1. Confusion Matrix

\begin{tabular}{|l|l|l|}
\hline \multirow{2}{*}{ Kelas } & \multicolumn{2}{|l|}{ Terklasifikasi } \\
\cline { 2 - 3 } & Lolos & Tidak Lolos \\
\hline Lolos & 40 & 0 \\
\hline Tidak Lolos & 6 & 19 \\
\hline
\end{tabular}

Pada tabel diatas True Positive adalah data yang berjumlah 40, False Negative adalah data yang berjumlah 0, False Positive adalah data yang berjumlah 6 , dan True Negative adalah data yang berjumlah 19 .

$$
\begin{aligned}
\text { Akurasi } & =\frac{T P+T N}{T P+T N+F P+F N} \times 100 \% \\
& =\frac{40+19}{40+19+6+0} \times 100 \% \\
& =\frac{59}{65} x 100 \%=91 \% \\
\text { Presisi } & =\frac{T P}{F P+T P} \times 100 \% \\
& =\frac{40}{6+40} \times 100 \% \\
& =\frac{40}{46} x 100 \%=87 \% \\
\text { Recall }= & \frac{T P}{F N+T P} \times 100 \% \\
& =\frac{40}{0+40} x 100 \% \\
& =\frac{40}{40} x 100 \%=100 \%
\end{aligned}
$$

Dari hasil perhitungan diatas didapat nilai akurasi sebesar $91 \%$, nilai presisi sebesar $87 \%$, dan nilai recall sebesar $100 \%$.

\subsection{Hasil Pengujian Akurasi Metode}

Dengan menggunakan data training sebanyak 10 data dengan nilai $\mathrm{K}=7$. Untuk mendapatkan keterangan dilakukan pencocokan antara hasil klasifikasi dari perhitungan yang dilakukan oleh sistem dengan perhitungan secara manual. Hasil pengujian ditunjukkan pada gambar 11
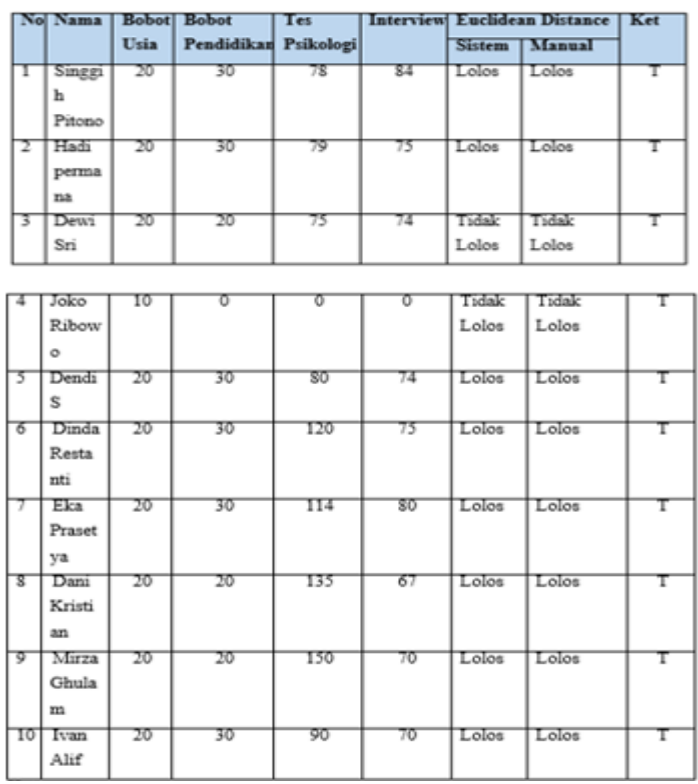

Gambar 11 Pengujian Akurasi Metode

Keterangan :

$\mathrm{T}=$ True. Terjadi apabila hasil perhitungan sistem sama dengan hasil manual. 
$\mathrm{F}=$ False. Terjadi apabila hasil perhitungan sistem berbeda dengan hasil manual.

Berdasarkan hasil pengujian sistem yang telah dilakukan dengan 10 data baru dan nilai $\mathrm{k}=7$, didapatkan 10 data diklasifikasikan dengan benar. Maka persentase pengujian sebagai berikut :

$$
\begin{aligned}
\text { Pengujian sistem } & =\frac{\text { banyak hasil pengujian benar }}{\text { banyak data training }} \times 100 \% \\
& =\frac{10}{10} \times 100 \%=100 \%
\end{aligned}
$$$$
\text { Persentase error }=\frac{(\text { hasil manual }- \text { hasil sistem })}{\text { hasil manual }} \times 100 \%
$$$$
=\frac{(10-10)}{10} \times 100 \%=0 \%
$$

Dari hasil pengujian sistem menunjukkan bahwa perhitungan dengan sistem sudah baik, sesuai dengan perhitungan metode secara manual.

\subsection{Pengujian Akurasi Program}

Pengujian akurasi program merupakan pengujian yang bertujuan untuk mengetahui hasil akurasi tingkat keberhasilan implementasi metode yang digunakan dengan hasil pada data yang sebenarnya. Pada pengujian ini menggunakan 10 data asli, kemudian data asli tersebut diuji cobakan pada sistem dengan parameter $K=7$. Hasil pengujian ditunjukkan pada gambar 12 :

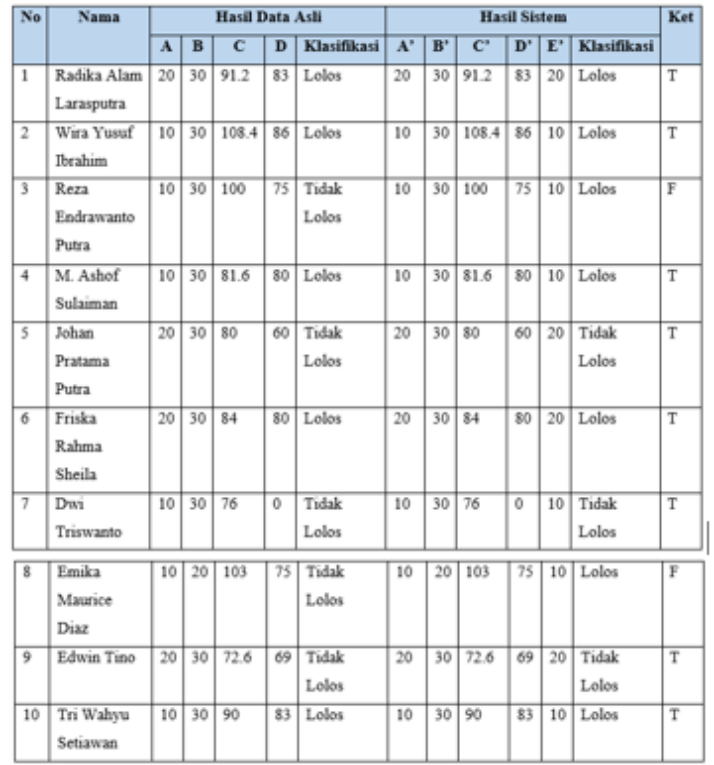

Gambar 12 Pengujian Akurasi Program

Keterangan :

$\mathrm{A} / \mathrm{A}^{\prime}=$ bobot usia, $\mathrm{B} / \mathrm{B}^{\prime}=$ bobot pendidikan, $\mathrm{C} / \mathrm{C}^{\prime}=$ tes psikologi, $\mathrm{D} / \mathrm{D}^{\prime}=$ hasil interview.

$\mathrm{T}=$ True. Terjadi apabila hasil perhitungan data asli sama dengan sistem.

$\mathrm{F}=$ False. Terjadi apabila hasil perhitungan data asli tidak sama dengan sistem.
Berdasarkan hasil pengujian sistem yang telah dilakukan dengan 10 data asli dan nilai $\mathrm{k}=7$, didapatkan 8 data diklasifikasikan sama dan 2 data diklasifikasikan berbeda. Maka persentase pengujian sebagai berikut :

$$
\begin{aligned}
\text { Persentase Akurasi } & =\frac{\text { banyak hasil pengujian benar }}{\text { banyak data }} \times 100 \% \\
& =\frac{8}{10} \times 100 \%=80 \% \\
\text { Persentase error } & =\frac{(\text { hasil manual }- \text { hasil sistem })}{\text { hasil manual }} \times 100 \% \\
& =\frac{(10-8)}{10} \times 100 \%=20 \%
\end{aligned}
$$

Dari hasil pengujian diatas perbandingan tingkat keberhasilan antara data asli dengan sistem sebesar $80 \%$ dan nilai error sebesar $20 \%$

\subsection{Pengujian Fungsional Menu Website}

Pengujian fungsional bertujuan untuk mengetahui apakah website yang dibuat dapat berjalan baik pada browser. Pada pengujian ini

\begin{tabular}{|c|c|c|c|}
\hline Akses & Fungsi & $\begin{array}{l}\mathbf{G} \\
\mathbf{C}\end{array}$ & $\begin{array}{l}\mathbf{M} \\
\mathbf{E}\end{array}$ \\
\hline \multirow{7}{*}{ Manager } & Halaman login & $\sqrt{ }$ & $\sqrt{ }$ \\
\hline & Proses login & $\sqrt{ }$ & $\sqrt{ }$ \\
\hline & Halaman registrasi & $\sqrt{ }$ & $\sqrt{ }$ \\
\hline & Proses registrasi & $\sqrt{ }$ & $\sqrt{ }$ \\
\hline & Halaman tampil data & $\sqrt{ }$ & $\sqrt{ }$ \\
\hline & Halaman hasil klasifikasi & $\sqrt{ }$ & $\sqrt{ }$ \\
\hline & Proses logout & $\sqrt{ }$ & $\sqrt{ }$ \\
\hline \multirow{17}{*}{ Admin } & Halaman login & $\sqrt{ }$ & $\sqrt{ }$ \\
\hline & Proses login & $\sqrt{ }$ & $\sqrt{ }$ \\
\hline & Halaman registrasi & $\sqrt{ }$ & $\sqrt{ }$ \\
\hline & Proses registrasi & $\sqrt{ }$ & $\sqrt{ }$ \\
\hline & Halaman tampil data & $\sqrt{ }$ & $\sqrt{ }$ \\
\hline & Halaman upload data & $\sqrt{ }$ & $\sqrt{ }$ \\
\hline & Proses upload & $\sqrt{ }$ & $\sqrt{ }$ \\
\hline & Halaman tambah data & $\sqrt{ }$ & $\sqrt{ }$ \\
\hline & Proses tambah data & $\sqrt{ }$ & $\sqrt{ }$ \\
\hline & Halaman edit data & $\sqrt{ }$ & $\sqrt{ }$ \\
\hline & Proses edit data & $\sqrt{ }$ & $\sqrt{ }$ \\
\hline & Proses hapus data & $\sqrt{ }$ & $\sqrt{ }$ \\
\hline & Halaman perhitungan & $\sqrt{ }$ & $\sqrt{ }$ \\
\hline & Proses perhitungan & $\sqrt{ }$ & $\sqrt{ }$ \\
\hline & Halaman hasil klasifikasi & $\sqrt{ }$ & $\sqrt{ }$ \\
\hline & $\begin{array}{l}\text { Proses hapus hasil } \\
\text { klasifikasi }\end{array}$ & $\sqrt{ }$ & $\sqrt{ }$ \\
\hline & Proses logout & $\mathrm{V}$ & $\sqrt{ }$ \\
\hline
\end{tabular}
menggunakan 2 web browser yaitu Google Chrome Versi 81.0.4044.138 dan Microsoft Edge Versi 38.14393.2068.0. Hasil pengujian terhadap web browser ditunjukkan pada tabel 2

Tabel 2. Pengujian Fungsional Menu Website 
Setelah dilakukan pengujian oleh 2 web browser, semua fungsi dari sistem berjalan dengan baik.

\subsection{Pengujian User}

Pengujian user adalah repon atau penilaian terhadap sistem yang dilakukan oleh user. Pada pengujian user ini, kuisioner diberikan kepada pihak hrd dan manajer pada BFI Finance Surabaya. Pengujian user ditunjukkan pada gambar 13

\begin{tabular}{|l|l|c|c|c|}
\hline No & \multicolumn{1}{|c|}{ Pertanyaan } & \multicolumn{3}{c|}{ Respond User } \\
\cline { 3 - 5 } & & Baik & Cukup & Kurang \\
\hline 1. & $\begin{array}{l}\text { Apakah ukuran dan warna font sudah } \\
\text { terlihat dengan jelas? }\end{array}$ & 1 & 1 & - \\
\hline 2. & $\begin{array}{l}\text { Apakah tampilan website sudah sesuai } \\
\text { kebutuhan? }\end{array}$ & 1 & 1 & - \\
\hline 3. & $\begin{array}{l}\text { Apakah warna tombol dan background } \\
\text { pada aplikasi sudah sesuai dan terlihat } \\
\text { jelas? }\end{array}$ & 2 & - & - \\
\hline 4. & $\begin{array}{l}\text { Apakah tampilan menu-menu program } \\
\text { mudah dipahami2 }\end{array}$ & 2 & - & - \\
\hline 5. & $\begin{array}{l}\text { Apakah form-form yang ada pada } \\
\text { program sudah sesuai? }\end{array}$ & 2 & - & - \\
\hline 6. & $\begin{array}{l}\text { Apakah program membantu } \\
\text { mempermudah proses seleksi calon } \\
\text { karyawan baru? }\end{array}$ & - & 2 & - \\
\hline \multicolumn{1}{|c|}{ Total } & $\mathbf{8}$ & $\mathbf{4}$ & - \\
\hline
\end{tabular}

Gambar 13 Hasil Pengujian User

\section{KESIMPULAN DAN SARAN}

\subsection{Kesimpulan}

Setelah dilakukannya pembuatan dan pengujian aplikasi Implementasi Metode K - Nearest Neighbor Untuk Seleksi Calon Karyawan Baru, maka dapat ditarik kesimpulan sebagai berikut :

1. Sistem ini dapat dijalankan pada browser Google Chrome dan Microsoft Edge dengan baik.

2. Berdasarkan hasil perhitungan algoritma $K$ Nearest Neighbor dengan nilai parameter K = 7 menggunakan metode Euclidean Distance didapat nilai akurasi sebesar $91 \%$, nilai presisi sebesar $87 \%$, dan nilai recall sebesar $100 \%$.

3. Berdasarkan hasil pengujian akurasi metode, yaitu perhitungan manual yang dilakukan menggunakan Microsoft Excel dengan perhitungan yang dilakukan oleh sistem menghasilkan persentase akurasi $100 \%$ dan persentase error sebesar $0 \%$

4. Berdasarkan hasil pengujian akurasi program, yaitu pengujian yang bertujuan untuk mengetahui hasil akurasi tingkat keberhasilan implementasi metode yang digunakan dengan hasil pada data yang sebenarnya menghasilkan persentase akurasi $80 \%$ dan persentase error sebesar $20 \%$

5. Berdasarkan hasil pengujian user yang dilakukan oleh 2 user mendapatkan jumlah nilai
8 untuk penilaian baik dan nilai 4 untuk penilaian cukup.

\subsection{Saran}

Berdasarkan peneltian yang telah dilakukan maka penulis dapat memberikan saran untuk pengembangan dan perbaikan kedepannya karena penelitian ini masih terdapat banyak kekurangan, sehingga perlu ada perbaikan dan penambahan sebagai berikut:

1. Untuk hasil yang lebih baik dapat dilakukan penambahan data - data sebagai data training sehingga lebih banyak data yang sebagai acuan proses klasifikasi.

2. Untuk mendapatkan hasil yang bervariasi dapat dibandingkan dengan metode klasifikasi yang lain.

\section{DAFTAR PUSTAKA}

[1] Supriana, I. W. \& Astuti, L. G., 2019. IMPLEMENTASI K-NEAREST NEIGHBOR PADA PENENTUAN KELUARGA MISKIN BAGI DINAS SOSIAL KABUPATEN TABANAN. Jurnal Teknologi Informasi Dan Komputer, Januari, Volume : 5(1), pp. 120-129.

[2] Alghifari, M. R. \& Wibowo, A. P., 2019. Penerapan Metode K-Nearest Neighbor Untuk Klasifikasi Kinerja Satpam Berbasis Web. Jurnal Teknologi \& Manajemen Informatika, Volume : 5(1), pp. 1-10.

[3] Dzikrulloh, N. N., I. \& Setiawan, B. D., 2017. Penerapan Metode K-Nearest Neighbor (KNN) dan Metode Weighted Product (WP) Dalam Penerimaan Calon Guru Dan Karyawan Tata Usaha Baru Berwawasan Teknologi (Studi Kasus : Sekolah Menengah Kejuruan Muhammadiyah 2 Kediri). Jurnal Pengembangan Teknologi Informasi dan Ilmu Komputer, Mei, Volume : 1(5), pp. 378-385.

[4] Auliasari, K \& Kertaningtyas, M., 2019. Penerapan Metode Peramalan Untuk Identifikasi Potensi Permintaan Konsumen. Informatics Journal, Desember, Vol. 4 No.3, pp. 121-129.

[5] Wardani, S. H., Rismawan, T. \& Bahri, S., 2016. Aplikasi Klasifikasi Jenis Tumbuhan Mangrove Berdasarkan Karakteristik Morfologi Menggunakan Metode K-Nearest Neighbor (KNN) Berbasis Web. Jurnal Coding, Sistem Komputer Untan, 04(3), pp. 9-21.

[6] Dzikrulloh, N. N., I. \& Setiawan, B. D., 2017. Penerapan Metode K-Nearest Neighbor (KNN) dan Metode Weighted Product (WP) Dalam Penerimaan Calon Guru Dan Karyawan Tata Usaha Baru Berwawasan Teknologi (Studi Kasus : Sekolah Menengah Kejuruan Muhammadiyah 2 Kediri). Jurnal Pengembangan Teknologi Informasi dan Ilmu Komputer, Mei, Volume : 1(5), pp. 378-385. 